\title{
GIScience for Sustainable Development
}

\author{
Mehrdad Jafari Salim \\ GIS \& SDI Department, National Cartographic Center, Tehran, Iran \\ Email: mehrdad_jafarisalim@yahoo.com
}

How to cite this paper: Jafari Salim, M. (2017) GIScience for Sustainable Development. Journal of Geographic Information System, 9, 482-492. https://doi.org/10.4236/jgis.2017.94030

Received: July 5, 2017

Accepted: August 12, 2017

Published: August 15, 2017

Copyright (c) 2017 by author and Scientific Research Publishing Inc. This work is licensed under the Creative Commons Attribution International License (CC BY 4.0).

http://creativecommons.org/licenses/by/4.0/ (c) (i)

\begin{abstract}
Due to the importance of development and its impact on our life, in this paper we are going to elaborate on the Sustainable Development and its related issues. In the following, due to the essential role that GIScience can play on the success trend of Sustainable Development, GIScience will be defined and its importance will be discussed as an effective tool in its logical procedure of Sustainable Development. The decision making support systems-using Geoinformation and spatial data-is merging increasingly into other disciplines design and techniques day by day. So It would be worth investigation on the technical aspects of sustainable development and its consideration in projects development in general, throughout the literature review and SD requirements. The successful sustained achievement will depend on clear "political" answerability for its reliability and local regulatory environment. It should be in harmony with the additional superior prescription and ruling at the national or international levels by the use and utilization of national spatial data infrastructure. The paper will ends up with a set of suggested practices in the development of Spatial Data Infrastructure (SDI).
\end{abstract}

\section{Keywords}

Sustainable Development, GIScience, Spatial Data Infrastructure

\section{Introduction}

In old ages and past centuries, the population of the world, the level of technology, and their environmental impact were all small and although there existed damages caused by human activities, but they could be corrected in time, often by mother of nature or it was negligible, non-critical and not so dangerous. But nowadays in twenty first century we have different situation where, in most of the cases like global warming, pollution in the air and sea, and etc. the environmental impact is so high and it requires massive effort by all nation to solve the problem and mother of nature is unable to correct it by itself and it is so dangerous to human kind. These types of phenomenon and conditions have their 
effects beyond the political boundaries, no respect for human being and its jurisdictions, culture and religion [1].

The problem is that it is almost impossible to anticipate with $100 \%$ certainty the consequences and the impacts over environment at the time of making the decision to develop [2]. Figure 1 shows the components of sustainable development.

It is interesting to note that apart from the war situation, there could be very few circumstances that humans have taken decisions deliberately to harm the planet. These types of the decisions could be made regardless to its consequences, often with economic motive in mind or with aim to improve things later on [4].

Here is the time that "sustainable development" comes into attention and becomes one of the most important issues on decision making for any types of development that human being need [5].

Apart from Environmental issues, there are other principles that affect sustainability of any types of development. These issues have to be precisely considered on decision making to guaranty its sustainable development.

These principles are [1]:

- Equity: The concerns for poor and disadvantaged;

- Futurity: The concern for future generation;

- Environment: The concern for the integrity of the eco-systems;

- Public participation: the concern that individual should have the opportunity to effect in decisions that may have consequences on their society;

With reference to the above mentioned principles, we are going to analyze different aspects of sustainable development and one of the tools for its evaluation "GIScience (Geo-information Science)". It plays different important roles in sustainable development evaluation [5]. It is not only a tool to provide spatial information required for sustainable development as a decision making support system, but also is used as an assessment tool for spatio-temporal analysis that sustainability is being realized during the pre-specified time span for target society [6].

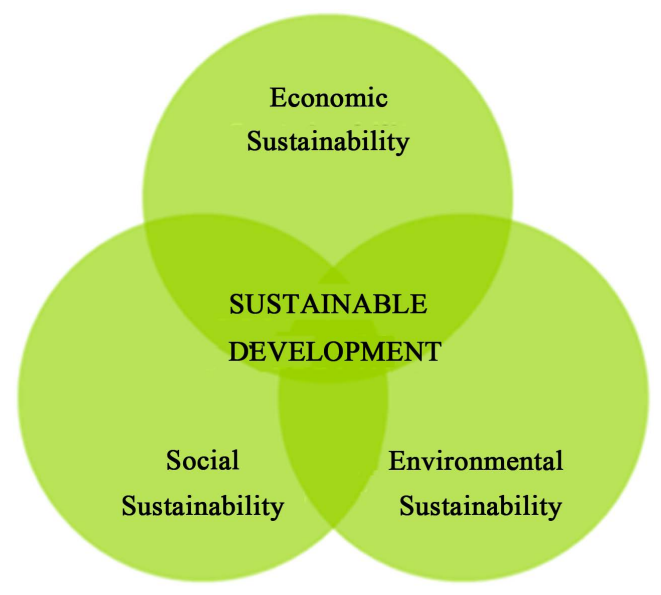

Figure 1. The components of sustainable development [3]. 


\section{Literature Review}

Yeh et al. in 1997, have studied the utilization of GIS and spatial information including remotely sensed data in urban growth elaboration in the Pearl River Delta land development [7].

Xiuwan et al. used a post-classification method in 2002 as change detection procedures using multi-temporal satellite images by the classification methods utilized on land cover developments. The spatial analysis methodology and applications in GiScience allows the study on implementation of sustainable development criteria on land cover developments [8].

Chowdary et al. in 2009 proposed a watershed development plans for Mayurakshi watershed in India by the use of remotely sensed data and GIS application. They adopted Integrated Mission for Sustainable Development (IMSD) principles and decision rules [9].

Bedi et al. studied the application of spatial data infrastructure for Sustainable Land Resource Management. Spatial Data Infrastructure (SDI), which contained various types of SDI development under National Spatial Data Infrastructure (NSDI), such as some organizational SDIs like National Urban Information System (NUIS), Environmental Information System (ENVIS) and other contributors to Indian SDI. It showed that it could be a very useful tool in bringing clarity and transparency in the development process. In fact the SDI can help the development process to follow in the rightful direction [10].

Wan et al. investigated the development of Hadaqi industrial corridor using GIScience and created a Dynamic Model for development of social and ecological environment [11].

In This paper we are going to see the crucial gain and improvement achievable by sustainable development with the use of GIScience and SDI application. All the above-mentioned papers shows various application of GIScience and SDI in Sustainable development but in this paper we are going to formulate the fundamental role of SDI in Sustainable Development.

\section{What Does "Sustainable Development" Mean?}

First of all, it's better to look at the root meaning of the sustainable development. To sustain means to continue without lessening, to nourish, to allow to flourish, to cause or allow something to continue for a period of time, to keep alive: with less damages to the environment for a long lasting benefit for the projects to continue and to develop means to improve or bring to a more advanced state; growth; progress [1].

Sustainable development is therefore about facilitating improvement without jeopardizing what exists already, or continuous growth. Practically saying the "sustainable" does not mean that nothing ever changes nor does it Utopia where nothing bad happens. It's not about maintaining the existing status or reaching perfection. At the same time "Development" does not mean continuously getting bigger but is about qualitative improvement. 
"Sustainable development" does not mean nonstop growth, at some points a community stops getting larger but it continues to improve the quality of life of its inhabitants. "Sustainable developments" means continuous improvement that comes with growth quality but it sometimes does not necessarily comes with growth size.

According to The Brundtland report "Sustainable development is development that meets the needs of the present without compromising the ability of future generations to meet their own needs" [12]. It extends its definition as: "In essence sustainable development is a process of change in which exploitation of resources, the direction of environments, the orientation of technological developments and institutional changes are all in harmony and enhance current and future potential to meet human needs and aspirations" [12].

\subsection{Environmental Concerns}

Sustainable development at the beginning initiated by the groups associated with the green movement who concerned about, the non-renewable resources (Energy stocks), the pollution of the air and water and globally speaking the destruction of environment and the balance of nature (the eco-system) which has a great impact over all living creatures. This subject focuses on the extent of the damages being done to the environment, the responsibility for the current situation. It also tries to elaborate the methods that must be taken in to the action to solve their negative impacts, leading toward promotion of consensus that something is wrong and all the human being has the duty to do something about it [1]. Of course choosing the right method is another matter because there is a spectrum of views. At one extreme side there is a group that suggests we should conserve the environment at all costs, meaning that human being should change the way of living and economic growth in order to reduce consumption.

On the other side of these environmental concerns, there are those who say that there must be "technical fixes" which can solve the problem of environmental issues and the science and technology can cure the nature balance disturbance. Therefore there is no need for such a conservative approach. They believe that market will increase inevitably the price of non-renewable resources and will justify the expenditure for the innovators to provide reasonable alternatives [1].

One of the important aspects of the above-mentioned point of views is that the earth has been in the worst situation ever since its formation and climatic changes urgently requires the mankind actions in order to avoid probable catastrophe and natural disaster caused by unbalanced eco-system.

\subsection{Time Concerns}

At the heart of sustainable development there are some assumptions about how long a development is expected to sustain. The answer could be: forever, or up until human lifetime or another answer might be until something comes along which is better or changes the reason for the continuation of that specific devel- 
opment.

The sustainable development must be evaluated and bound in a specific time frame. If we take the very long term perhaps, we will not be able to correctly measure the direction and magnitude of our progress according to its corresponding condition. For example in GIScience with the invention of GPS and Digital cartographic hardware and software there was a fear of unemployment growth in cartography community and therefore sustainable development in Geomatics technology. It was a correct inference with the existing demands and way of thinking at the early 80 's among the Geomatics community. But the passing time has shown that the conditions in Geomatics world changed its expansion trend in opposite direction and the current situation is far from what we anticipated on that time on early 80 's.

At the same time if we take the short term, it would be impossible to realize the real impact and future outcome of what we have made, for example: in area of non-renewable resources, for sure we do not know what kinds of, benefits to health, good materials, and supply of useful products these materials can bring to our life because of our limited knowledge about their potential properties. We do not understand how differently they could be used in complex combinations linked to other knowledge.

In fact we value theses resources according to our current knowledge about what they can provide us, not according to what their potential benefit in future could be

\subsection{Global Problem and International Policy Concerns}

Now a day's, most of the subjects and problems facing human kinds are not confined within national boundaries, from a hole in the ozone layer or leak from a nuclear energy plant to drug addiction and disease contamination; from natural disaster (i.e. earthquake, river flood, volcano eruption) to political conflicts and society unrest and turmoil.

Since 1970's, international conferences and events show the development of world approach to address the issues in sustainable development. At the Rio earth summit in 1992 a significant changes took place and an agenda was agreed and signed by 179 world government. They defined sustainability in a new way, extending its boundaries beyond just environmental issues. This change was realized by the notion that environmental issues often have their origins in the behavior of the human race. When there are big differences between those who have and those who have not, unrest can follow and damage to sustainability can be substantial. The treat of terrorists gaining access to nuclear bombs or chemical weapon is now spoken openly, it all derived from unsolved and incorrect political, economical, and sociological behavior of national and international governing bodies.

Globally, a complex network of issues leads to actions that eventually have an impact on the environment and the way that we live affect the world on a global scale. 
Mitchell, et al. (1995) has concluded from the Rio's literature and other reports four principal which underlie the guidance and advice. It takes us the sustainable development beyond the pure environmental agenda.

These principles as stated before included, Equity, Futurity, Environment, and Public participation.

The focus of our debate has therefore been extended into new realm concerned with Social, Legal, Economic, Political and technical aspects of how we live (commonly known under the acronym SLEPT).

In another words we try to have transition from the general environmental debate to the wider discourse which includes those factors that influence the environment.

\section{GIScience Application in Sustainable Development}

With reference to what we have discussed previously, Sustainable Development vitally needs GIScience, theoretically and practically, in different aspects, and this is going to be elaborated during the rest of this paper.

Before anything else, it's necessary to mention the fact that, whatever exists in globe and universe has an inseparable component and this is nothing but its positional information as its primary attribute. This is one of the unique, comprehensive and magnificent properties of everything dead or alive creature in universe. This is one of the most exclusive characteristic of all phenomena in the world like finger print or DNA. Everything may perhaps change its location but it always has coordinate, as its attribute attached to it in its whole life span. It is true not only for physical objects but also for semantic and subject. In fact, whatever semantic information exists there should be a reference position as its appearance realization place. Sometimes the scale or the accuracy is so high sometimes it's low and rough. Figure 2 shows the analytical spatial zoning as an evaluation tools with reference to sustainability criteria.

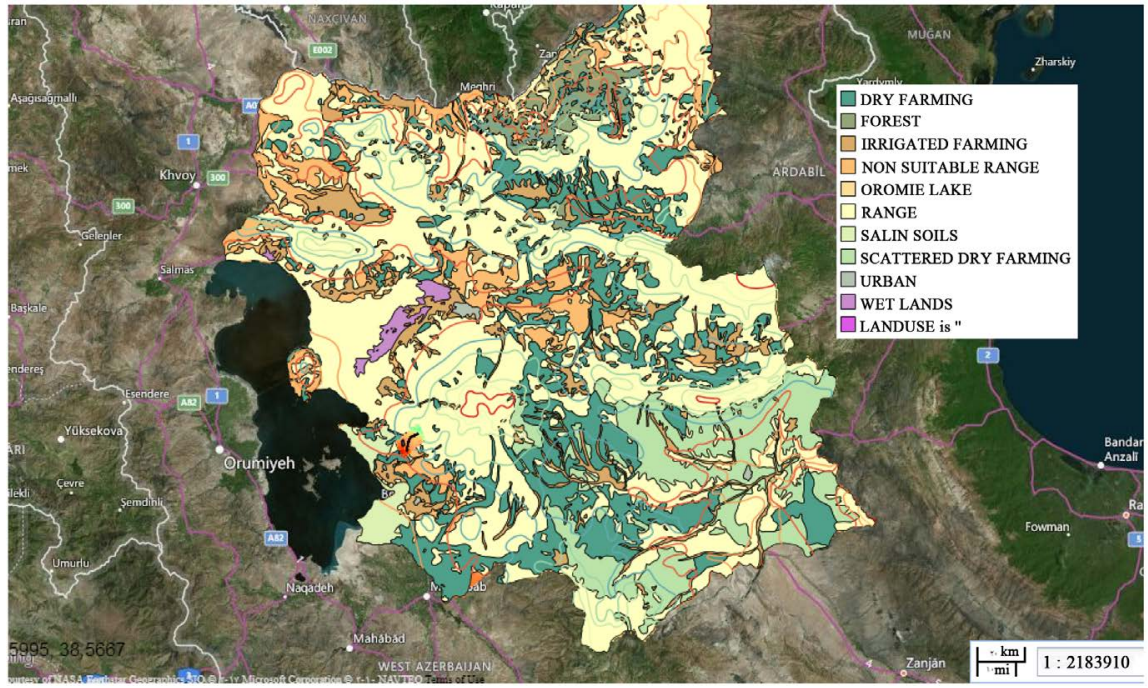

Figure 2. Zoning spatial data with reference to sustainability criteria. 


\subsection{During Reconnaissance Phase}

Having more detailed and comprehensive Geographic information as well as better tools leads toward better applications of GIS and remote sensing for sustainable development. Are the human resources, hardware, software, data and technical capacities found in developing-world sufficient for advancing sustainable development goals?

Base maps are driven from aerial/satellite imagery or paper maps, and produced on hardcopy or digitally on computer. Other disciplines fill in these maps or add their own knowledge and attributes as some layers of thematic information. In this stage, we develop scenarios of what a territory or landscape might look like given sets of land use decisions. We can also create virtual reality and computer models and "fly-through" techniques to simulate the probable consequences of land changes decisions.

Our ability to estimate all the challenges related to a hypothetical Sustainable Development, depends largely upon capacity-building for Spatial Data infrastructure (SDI) content and GIS professionals in developing societies. At the same time, increased information exchanges and data sharing policies towards maximum use of geographic information involved in any project guaranty the best alternative projects and its sustainability. There are three broad categories of GIS applications-participatory mapping (data sharing), land use mapping and geographic analysis of development problems. Availability of all these geographic information, remote sensing and GIScience throughout SDI, support our work in Sustainable Development.

\subsection{During Planning Phase, as Decision Making Support}

One of the main tasks of the GIScience that can help Sustainable Development is enrichment of Geographic database with all the possible means and all aspects providing comprehensive information for better analysis in any types of Decision Making Support.

Two decades ago government offices rarely had computers or digital data, preventing the possibility to do GIS analysis, but today, local governments in developing countries not only in mapping agencies but also in various disciplines are using geographic information technology. Most of their job has been creation of their own digital map layers, such as agricultural projects that are consisted of locating villages and their farms with GPS devices. Then, data collected for each village is linked to the location on a map or added to topographic base maps containing general topographic data. Integrated data with the help of spatial analysis tools allow more analysis of information in complex problem which cannot be accomplished in the normal management sense or visual interpretation. For example, one of the approaches used at local scales is so called as ecological and economic zoning. The area is divided into homogenous zones based on the biophysical potential of the land or socio-economic conditions.

These processes can be broadly introduced as applied GIScience. Scales of the maps as well as data contents in decision-making at all level, and the capacities 
to implement geographic information technology is also a very important element that must be considered wisely.

The capabilities to simulate the alternative land use scenarios enable more objective way of evaluating the effect of the simulations on future land use decisions. Ideal future for Sustainable Development would be the integration of multi disciplinary updated information gathered together throughout a service oriented distributed databases within a National Spatial Data Infrastructure.

For instance we can use GIScience to make poverty maps for a region and superimpose it with other existing maps about correlating parameters, like road network, weather condition, soil types, genetic distribution of specific crop, and ... targeting any possible analytical research in a specific area. This scenario requires that we have all the information about the client subjects and related information with regards to the existing scenario of our project with respect to natural resources, access to markets and socioeconomic setting.

Achieving agreements among various key role players in the Geomatics community remains a major challenge to GIS applications and Comprehensive Spatial Data Infrastructure [13].

GIS technology is increasingly playing a facilitating role for improved decision-making. Different data producer with various interest can share their knowledge of their local area to fill in maps to create rich data bases in order to make working environment of what they want their community to be like. This conclusive mapping methods can take place in an interconnected electronic government community. This method can contain wide spectrum ranges of data from simple sketch mapping to complex projecting computer-generated maps out of GIS analysis. In fact, maps and GIScience can be a Common language between stakeholders.

\subsection{During the Development}

Studies have shown substantial savings when routes and schedules are managed using GIS. During the development according to the plan, the desired conditions for the projects, society, municipality, or... can be discussed in a group in workshops with the community. Then the existing situation as well as desirable output can be analyzed and compared. The diagnosis on the causes of the gap between actual and desired conditions can be defined, and afterwards preliminary list of actions and requests could be collectively drawn.

Updated geographic data can be used to verify the validity of locally perceived trends. It can also be used to make the goals of planned actions more precise. In fact the geographic information database is used as the basis for monitoring the progress of the actions towards the goal.

Along with the projects evolving trends, simulations methods for alternative land use scenarios can provide possibilities with more objective way of evaluating the effects of the future land use decisions. This is GIS and project control's methods in future for meeting Sustainable Development.

Using GIScience facilitates the diagnosis, a stage in which many planners get 
into trouble when they gather large amount of information without having appropriate tools to fuse and combine them together as well as applications to demonstrate the effects of changing parameters in one item from one subjects and its effects on other subjects accordingly [13]. With this approach, the geographic data is used to determine if the land can sustain these activities, and how desirable uses and activities can be optimally located within the territory. Besides, the Land evaluation becomes an abstract and intermediate step in the process of Sustainable Development assessment. This concept leads us towards one of the most important aspects of GIS in use which is the necessity for continuous gathering of new data and endless correction of existing data.

\subsection{During the Evaluation Phase}

Since there is no very well defined boundaries between the last 3 steps-meaning the project planning phase, during the development, and evaluation phase-a sustainable development requires a continuous changes between these three stages. It means that we need to monitor continuously interdependent complex issues utilizing GIScience, leading to a new decision with respect to the existing condition. All the services, techniques and facilities provided by GIScience mentioned in previous phases can be applied in evaluation phase. But at the same time GIScience can help measure the indicators (Referring to the Section "Set of shared values \& Common framework-Measurement and Assessment") according to different evaluation concepts, like, ecological footprints, natural, human, and financial capital [14].

\section{Conclusions}

Today, by using GISceince and the related analysis, there are tremendous facilities to provide the advanced environment for human's lives by means of infrastructure data. The paramount role of spatial data and its application in promotion of the human's lives has been confirmed throughout the human history. Therefore, the GISceince can be utilized for providing sustainable development for modern societies which should use the latest advanced technologies to serve their nation appropriately. Based on the current needs in every society, it seems that by using Spatial Data Infrastructure as well as applying new standards and technologies, we, gradually, can get closer to the advanced sustainable development.

Research in visualization as a means of communicating is a high-priority need among the remote sensing and geographic information professional community.

As we discussed in first part of this paper when we talk about the agreement, the improved use of visualization in geographic information technology adapted to existing data resolution is necessary. Although it is difficult to measure the impact of visualization exercises, but It must be noted that cartographic enhancement and visualization techniques increase awareness, giving decisionmakers new knowledge and perspectives of the future impact about the likely outcomes of their decisions. 
Participatory mapping, computer simulation and standard cartographic presentation techniques hold out promise for more effective communication with decision-makers and the public, and it would certainly requires future research and development.

According to what we have discussed so far, GIScience can play positively in sustainable development in four different phases and roles as follows:

1) Reconnaissance phase (Phase zero) as initial data collection stage;

2) During planning phase, as decision making support;

3) During the development as a tool to help to sustain the development, and guaranty improvement of development factors;

4) For the evaluation phase as a tool to check if the project is developing along the right path and toward the correct.

\section{References}

[1] Brandon, P.S. and Lombardi, P. (2010) Evaluating Sustainable Development in the Built Environment. John Wiley \& Sons, New York.

[2] Larco, N. (2016) Sustainable Urban Design-A (Draft) Framework. Journal of Urban Design, 21, 1-29. https://doi.org/10.1080/13574809.2015.1071649

[3] https://macaulay.cuny.edu/eportfolios/akurry/2011/12/21/sustainable-development/

[4] Brandon, P.S., Lombardi, P. and Shen, G.Q. (2017) Future Challenges in Evaluating and Managing Sustainable Development in the Built Environment. John Wiley \& Sons, New York. https://doi.org/10.1002/9781119190691

[5] Verburg, P.H., et al. (2015) Land System Science and Sustainable Development of the Earth System: A Global Land Project Perspective. Anthropocene, 12, 29-41.

[6] Wan, L., et al. (2017) A Study of Regional Sustainable Development Based on GIS/RS and SD Model-Case of Hadaqi Industrial Corridor. Journal of Cleaner Production, 142, 654-662.

[7] Yeh, A.G. and Xia, L. (1997) An Integrated Remote Sensing and GIS Approach in the Monitoring and Evaluation of Rapid Urban Growth for Sustainable Development in the Pearl River Delta, China. International Planning Studies, 2, 193-210. https://doi.org/10.1080/13563479708721678

[8] Chen, X. (2002) Using Remote Sensing and GIS to Analyse Land Cover Change and Its Impacts on Regional Sustainable Development. International Journal of Remote Sensing, 23, 107-124. https://doi.org/10.1080/01431160010007051

[9] Chowdary, V.M., et al. (2009) Integrated Water Resource Development Plan for Sustainable Management of Mayurakshi Watershed, India Using Remote Sensing and GIS. Water Resources Management, 23, 1581-1602.

https://doi.org/10.1007/s11269-008-9342-9

[10] Bedi, P., et al. Integrating Spatial Database Infrastructure for Sustainable Land Resource Management, Nagaland, India. GSDI 15 World Conference.

[11] Wan, L., et al. (2016) A Study of Regional Sustainable Development Based on GIS/RS and SD Model-Case of Hadaqi Industrial Corridor. Journal of Cleaner Production, 142, 654-662.

[12] Keeble, B.R. (1988) The Brundtland Report: "Our Common Future". Medicine and War, 4, 17-25. https://doi.org/10.1080/07488008808408783

[13] Jafari Salim, M. (2014) The Analysis of Open Source Software and Data for Estab- 
lishment of GIS Services Throughout the Network in a Mapping Organization at National or International Level. Ph.D. Thesis, Polytecnico di Torino, Italy.

[14] Curwell, S.R., Deakin, M. and Symes, M. (2005) Sustainable Urban Development: The Environmental Assessment Methods. Vol. 2, Taylor \& Francis.

Submit or recommend next manuscript to SCIRP and we will provide best service for you:

Accepting pre-submission inquiries through Email, Facebook, LinkedIn, Twitter, etc. A wide selection of journals (inclusive of 9 subjects, more than 200 journals)

Providing 24-hour high-quality service

User-friendly online submission system

Fair and swift peer-review system

Efficient typesetting and proofreading procedure

Display of the result of downloads and visits, as well as the number of cited articles Maximum dissemination of your research work

Submit your manuscript at: http://papersubmission.scirp.org/

Or contact jgis@scirp.org 